\title{
TESTING TWO NUTRIENT PROFILING MODELS OF LABELLED FOODS AND BEVERAGES MARKETED IN TURKEY
}

\author{
Derya Dikmen, Mevlüde Kızıl, Muhemmet Fatih Uyar, Gülden Pekcan \\ Department of Nutrition and Dietetics, Faculty of Health Sciences, Hacettepe University, Ankara, Turkey
}

\section{SUMMARY}

Aim: The objective of this study was to evaluate the nutrient profile of labelled foods and also understand the application of two international nutrient profiling models of labelled foods and beverages.

Methods: WXYfm and NRF 9.3 nutrient profiling models were used to evaluate 3,171 labelled foods and beverages of 38 food categories and 500 different brands.

Results: According to the WXYfm model, pasta, grains and legumes and frozen foods had the best scores whereas oils had the worst scores. According to the NRF 9.3 model per $100 \mathrm{kcal}$, the best scores were obtained for frozen foods, grains and legumes and milk products whereas the confectionery foods had the worst scores. According to NRF 9.3 per serving size, grains and legumes had the best scores and flavoured milks had the worst scores. A comparison of WXYfm and NRF 9.3 nutrient profiling models ranked scores showed a high positive correlation $(p=0.01)$.

Conclusions: The two nutrient models evaluated yielded similar results. Further studies are needed to test other category specific nutrient profiling models in order to understand how different models behave.

Key words: nutrient profiles, labelled foods, nutritional quality

Address for correspondence: D. Dikmen, Department of Nutrition and Dietetics, Faculty of Health Sciences, Hacettepe University, 06100, Ankara, Turkey. E-mail: ddikmen@hacettepe.edu.tr

\section{INTRODUCTION}

Current evidence indicates that four types of non-communicable diseases (NCDs), cardiovascular disease, cancer, diabetes, and chronic respiratory disease, are the leading global causes of death, accounting for 36 million (63\%) of the 57 million global deaths in 2008 (1). NCDs are largely preventable and also some preventive interventions early in the course of life offer lifelong benefits $(1,2)$. Reducing salt levels, eliminating industrially produced transfatty acids, decreasing saturated fats, limiting free sugars, and providing accurate information to consumers in the form of nutrition labels are effective interventions to tackle NCDs (2).

Nutrient profiling could help to frame nutritional communication and guide consumers by positioning particular foodstuffs regarding their contribution to a healthful diet (3).

The European Food Safety Authority (EFSA) defines 'nutrient profile' as "the nutrient composition of a food or diet" and 'nutrient profiling' as "the classification of foods for specific purposes based on their nutrient composition" (4). The World Health Organization (WHO) defines the term 'nutrient profiling' as "the science of classifying or ranking foods according to their nutritional composition for reasons related to preventing diseases related with nutrition and promoting health" (5). Scientists, manufacturers, health organizations and government-sponsored programmes have developed many of the nutrient profiling models for education and dietary guidance, regulation of health claims, and evaluation of the nutritional quality of food products (6). Nutrient profile models can be divided into two groups according to their purpose of application: for the nutrient levels in foods (e.g. high fat, low fat, reduced fat, source of fibre, high in fat, sugars or salt/sodium, energy dense, nutrient poor); and directly for the effects of consuming the food on a person's health (e.g. healthy, healthier option, less healthy) (5).

The purpose of the nutrient profiling models differs in the European Union (EU) and the United States (US). In the EU, nutrient profiling models identify the foods eligible for nutrition claims and regulatory issues, whereas in the US they are mainly used for consumer guidance (7).

The Ofcom-WXYfm model was developed in 2004 for the Food Standards Agency (FSA) in order to regulate television advertising of foods for children in the UK. The model is based on calculation of the scores of nutrients according to set thresholds (8). The Nutrient Rich Food Index 9.3 was developed $(9,10)$ with the aim of evaluation of the nutritional quality of foods and beverages, education and consumer guidance (11). The NRF9.3 index is an algorithm based on subtracting the scores of the negative nutrients from the positive nutrients (12).

Nutrient profiling is a growing issue in Turkey. However, there is no research concerned with nutrient profiling of foods. This is the first study on the evaluation of nutrient profiling models in packaged foods and beverages marketed in Turkey.

Our objective was to evaluate the nutrient profiling of labelled foods and also understand the application of two internationally validated nutrient profiling models using the Food Standards Agency (FSA) FSA-Ofcom WXY and the Nutrient Rich Food Index 9.3 (NRF 9.3), that is the regulation of advertising to children and consumer guidance. 


\section{MATERIALS AND METHODS}

In this study the nutrition labels of dairy foods, processed meats, bread and cereals, chocolates, crisps, fruit juices and other beverages, ready to eat soups and other packaged foods marketed in two supermarkets in Ankara, Turkey, were evaluated. In Turkey, red meat, vegetables and fruits are sold unpackaged and for that reason these products were not evaluated in this study. Nutrition label information was entered on a form developed by the researcher. Energy, saturated fat, transfatty acids, sodium, added sugar, fiber, and all nutrient information on the labels were entered on the standardized form. All the food and beverage nutrition information were collected in order to evaluate the nutritional labelling situation in Turkey, since nutritional labelling is currently not compulsory unless a nutrition claim is made.

The nutrition information of the food and beverages were transferred to the SPSS program (version 15.0, SPSS Inc., Chicago, IL, 2006) and divided into food groups on the basis of the European Commission working document on the setting of nutrient profiles, the Preliminary Draft Legal Proposal (13), before any assessment. All the food and beverages were given an 8 digit code according to their food groups, brand name, food category, and the content of the food. Nutrient profiling scores were calculated according to the principles of the two systems for each food and beverage.

To obtain nutrition data, product labels were considered as the primary source, but in case of missing values, data were collected by searching manufacturer's websites, nutrition composition databases (14) and the Nutrition Information Systems Program 6.1 (BEBIS 6.1) (15)
In total, 3,184 labelled foods and beverages from 38 food categories and 500 different brands were collected and evaluated (Table 1). Natural mineral water had mineral content information on the nutrition label but had no macronutrient content, so thirteen natural mineral waters were excluded from the evaluation process. In this study, two nutrient profiling models were applied to 3,171 labelled foods and beverages and nutrient profiling models were compared according to their determined scores.

\section{The Nutrient Profiling Systems}

\section{WXYfm (FSA-Ofcom) Model}

Model WXYfm (FSA-Ofcom) was developed for the Food Standard Agency in the United Kingdom $(8,16,17)$ and provides the scientific basis for regulation of advertising aimed at children. In 2011, with changes in calculations it became model WXYfm (FSA-Ofcom) (17). Model WXYfm (Table 2) is based on energy, saturated fat, total sugars, and sodium as negative nutrients and protein, non-starch polysaccharide fiber and the content of the product's fruit, vegetables and nuts as positive nutrients, per $100 \mathrm{~g}$. The model is a simple scoring system that categorizes foods as 'less healthy' if the scores are greater than 4 or 'healthier' if the scores are less than 4. Furthermore, beverages are categorized as 'less healthy' if they score greater than 1 and 'healthier' if they score less than 1 (8). The model was validated by Arambepola et al. (18).

\section{Nutrient Rich Food Index (NRF 9.3.)}

Drewnowski et al. $(9,10)$ developed the Nutrient Rich Food Index 9.3. (NRF 9.3), which is based on a scoring system that

Table 1. Categorisation of examined labelled foods and beverages with food codes

\begin{tabular}{|c|c|c|c|}
\hline Food code & Food categories & Food code & Food categories \\
\hline 1 & Soft drinks (non-alcoholic beverages) & 20 & Yoghurt \\
\hline 2 & Fruit, vegetable juice & 21 & Ayran (Diluted yoghurt) \\
\hline 3 & Soda with fruit flavour & 22 & Probiotic yoghurts \\
\hline 4 & Biscuits & 23 & Milks \\
\hline 5 & Cakes & 24 & Flavoured milks \\
\hline 6 & Chocolates & 25 & Pudding, flavoured yoghurt for children \\
\hline 7 & Chocolate coated wafers & 26 & Ice creams \\
\hline 8 & Chocolate cream spread & 27 & Ready to eat foods \\
\hline 9 & Non-chocolate confectionary & 28 & Soups (powdered) \\
\hline 10 & Sweets, candies & 29 & Canned fish \\
\hline 11 & Honey, jam, concentrated grape juice & 30 & $\begin{array}{l}\text { Meat and processed meat products (salami, sausages, sucuk, jambon, } \\
\text { pastirma, chicken meat) }\end{array}$ \\
\hline 12 & Crisps & 31 & Frozen foods (frozen vegetables, fruits, frozen doughs, frozen meats) \\
\hline 13 & Breads & 32 & Canned foods (vegetables) \\
\hline 14 & Fine bakery wares & 33 & Vegetable oils and spreads \\
\hline 15 & Pasta & 34 & Olives \\
\hline 16 & Grains, legumes & 35 & Pudding mix (powdered) \\
\hline 17 & Nuts, dried fruits & 36 & Tomato sauce, ketchup, mayonnaise \\
\hline 18 & Breakfast cereals & 37 & Pickles \\
\hline 19 & Cheeses & 38 & Gums \\
\hline
\end{tabular}


ranks foods according to their nutrient content (9). The NRF 9.3 model (Table 2) accepts protein, fiber, iron, calcium, potassium, magnesium, and vitamins $\mathrm{A}, \mathrm{C}$, and $\mathrm{E}$ as positive nutrients, whereas saturated fat, added sugar, and sodium are considered negative nutrients, per $100 \mathrm{kcal}$ or serving size of food $(9,10)$. In the NRF 9.3 model, the higher the score for a food, the healthier choice it is. The model was validated using the Healthy Eating Index (19). In this model the serving size is calculated according to the Turkish Food Codex, the Food Labelling Regulation of food portion sizes (20).

The SPSS (version 15.0, SPSS Inc., Chicago, IL, 2006) package was used in the statistical analyses and ranking was made for Ofcom WXYfm and NRF 9.3 nutrient profiling model scores. In order to compare the nutrient profiles, the Spearman correlation was used for the correlation between rank scores. Regression analysis was used to show the strength of the correlation between the energy value of the foods and beverages and the nutrient profiling scores. In statistical tests, a $p$ value $<0.05$ was considered significant.

\section{RESULTS}

Figure 1 shows the distribution of the labelled foods and beverages according to their energy values and WXY fm model scores. Calculations for the foods and beverages using the WXYfm model generated the best score for pasta ( -5.39 points), grains and legumes ( -4.22 points), and frozen foods ( -2.52 points) and the worst score for oils (18.78 points). More energy dense foods have higher scores and they were categorized as less healthy under this model. There was a moderate correlation between energy values and the WXY fm scores of the foods and beverages $(r=0.557, \mathrm{p}<0.05)$.

Figures 2 and 3 show the distribution of the foods and beverages according to the NRF 9.3 index model and their energy values. The NRF 9.3 index scores were calculated per $100 \mathrm{kcal}$ or per serving size. With the NRF 9.3 model, per $100 \mathrm{kcal}$ (Fig. 2), the best scores were determined for frozen foods ( 8.63 points), grains and legumes (4.21 points), and milk and milk products (4.11 points), while the confectionery foods ( -14.43 points) received the worst scores. On the other hand, the NRF 9.3 model per serving size obtained the highest score for grains and legumes (7.51 points) and the lowest score for flavoured milks ( -21.53 points). As seen in the Figure 3, the NRF 9.3 model per serving size generated higher scores for milk, types of cheeses, grains and legumes. There was no statistically significant correlation between energy density and the scores of the NRF 9.3 index model per $100 \mathrm{kcal}$ and per serving size $(r=0.11, p>0.05, r=0.13, p>0.05$, respectively).

When the scores of NRF 9.3 per kcal and NRF 9.3 index per serving were compared with the Spearman correlation, a statistically significant difference $(p=0.01, r=0.896)$ was observed.

Table 3 compares the scores of some food groups according to WXYfm and NRF 9.3 index ( $100 \mathrm{kcal} /$ serving size). Rank scores are provided according to the mean scores of the food groups. The WXYfm model is based on energy, saturated fat and sugar content of the foods and beverages. The WXYfm model generated the worst scores for cheeses, cakes, chocolates, vegetable

Table 2. Summary of the selected nutrient profiling models $(9,10,16,17,18)$

\begin{tabular}{|l|c|c|}
\hline & WXYfm Model & Nutrient Rich Food NRF 9.3 Model \\
\hline Aim & $\begin{array}{c}\text { Eligibility for marketing programmes/Advertisements } \\
\text { aimed at children }\end{array}$ & Evaluation of the nutritional quality/Nutrition education \\
\hline Categories & Across the board & Across the board \\
\hline Calculation & Scoring/Categorisation & Scoring \\
\hline Nutrient selection (negative/positive) & $4 / 3$ & $3 / 9$ \\
\hline & $\begin{array}{c}\text { Energy, saturated fat, total sugars, and sodium } \\
\text { (negative nutrients); protein, nonstarchpolysac- } \\
\text { charide fiber and the content of the products fruit, } \\
\text { vegetable and nut (positive nutrients) }\end{array}$ & $\begin{array}{c}\text { Saturated fat, added sugar, and sodium (negative } \\
\text { nutrients); protein, fiber, iron, calcium, potassium, } \\
\text { magnesium, and vitamins A, C, and E (positive } \\
\text { nutrients) }\end{array}$ \\
\hline Reference Amount & \multicolumn{1}{|c|}{$100 \mathrm{~g}$} & Serving size/100 kcal \\
\hline
\end{tabular}

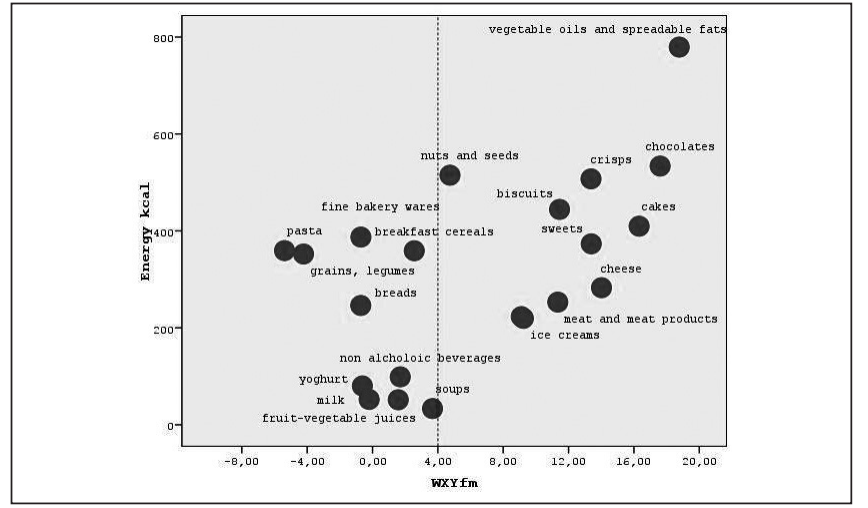

Fig. 1. Distribution of the food groups according to their $W X Y$ fm score and energy $(r=0.557, p<0.05)$.

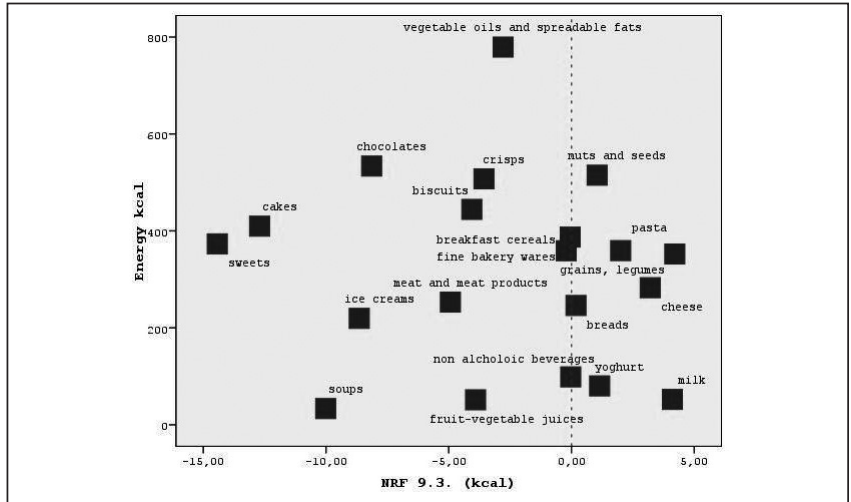

Fig. 2. Distribution of the food groups according to NRF 9.3 index score per $100 \mathrm{kcal}$ and energy value $(r=0.11, p>0.05)$. 


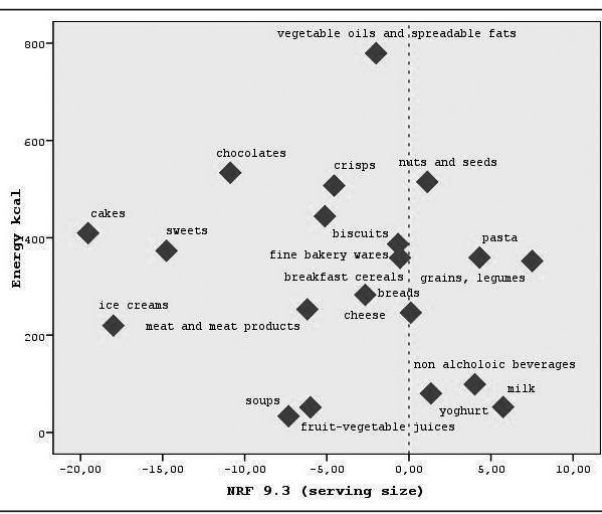

Fig. 3. Distribution of the food groups according to NRF 9.3 index score per serving size and energy value $(r=0.13, p>0.05)$.

oils, and spread fats. Cheeses were penalized in the WXYfm model depending on the saturated fatty acid content of the cheese products. Grains, legumes, nuts, and dried fruits are energy dense foods but their scores were relatively high and considered to be healthier in this model. The NRF 9.3 index per $100 \mathrm{kcal}$ and per serving size had a correlation of ranked scores but it is interesting that there was no statistically significant correlation between the scores and the energy value of the foods.

Table 4 represents the Spearman correlation of the rank scores of two continuous models. The results indicated a significant correlation between the models $(p=0.01)$.

Table 4. Spearman correlation of nutrient profiling models

\begin{tabular}{|l|c|c|c|}
\hline & WXY & NRF 9.3 kcal & NRF 9.3. serving \\
\hline WXYfm & 1.000 & $0.653^{*}$ & $0.654^{*}$ \\
\hline NRF 9.3 kcal & $0.653^{*}$ & 1.000 & $0.928^{*}$ \\
\hline NRF 9.3. serving & $0.654^{*}$ & $0.928^{*}$ & 1.000 \\
\hline
\end{tabular}

${ }^{*} p=0.01$

Table 3. Comparing rank scores of WXYfm and NRF 9.3 Index Models

\begin{tabular}{|c|c|c|c|c|c|c|}
\hline Food groups & Rank WXYfm & WXYfm score & $\begin{array}{c}\text { Rank NRF } \\
9.3 \text { kcal }\end{array}$ & $\begin{array}{l}\text { NRF } 9.3 \text { (kcal) } \\
\text { score }\end{array}$ & $\begin{array}{c}\text { Rank NRF } 9.3 \\
\text { (serving) }\end{array}$ & $\begin{array}{c}\text { NRF } 9.3 \\
\text { (serving) score }\end{array}$ \\
\hline Pasta & 1 & -5.39 & 6 & 2 & 4 & 4.3 \\
\hline Grains, legumes & 2 & -4.22 & 2 & 4.21 & 1 & 7.51 \\
\hline Frozen foods & 3 & -2.52 & 1 & 8.63 & 2 & 5.97 \\
\hline Canned foods & 4 & -1.19 & 7 & 1.93 & 9 & 0.51 \\
\hline Ayran (beverage of yoghurt diluted with water) & 5 & -1.11 & 4 & 3.76 & 6 & 3.89 \\
\hline Breads & 6 & -0.72 & 10 & 0.19 & 10 & 0.12 \\
\hline Fine bakery wares & 7 & -0.71 & 12 & -0.05 & 12 & -0.66 \\
\hline Yoghurts & 8 & -0.62 & 8 & 1.15 & 7 & 1.34 \\
\hline Milk & 9 & -0.21 & 3 & 4.11 & 3 & 5.74 \\
\hline Soda with fruit flavoured & 10 & 0.47 & 23 & -7.14 & 22 & -6.6 \\
\hline Ready to eat foods & 11 & 0.79 & 14 & -0.38 & 13 & -1.58 \\
\hline Fruit and vegetable juice & 12 & 1.57 & 18 & -3.91 & 20 & -6 \\
\hline Flavoured milk etc. & 13 & 1.69 & 29 & -11.95 & 31 & -21.53 \\
\hline Soft drinks (non alcoholic beverages) & 14 & 1.7 & 11 & -0.03 & 5 & 4.02 \\
\hline Breakfast cereals & 15 & 2.56 & 13 & -0.21 & 11 & -0.54 \\
\hline Ready to eat soups & 16 & 3.67 & 27 & -10.01 & 24 & -7.33 \\
\hline Nuts, dried fruits & 17 & 4.74 & 9 & 1.05 & 8 & 1.12 \\
\hline Non-chocolate confectionary & 18 & 7 & 24 & -7.66 & 19 & -583 \\
\hline Canned fish & 19 & 9.11 & 16 & -2.8 & 15 & -2.64 \\
\hline Ice cream & 20 & 9.23 & 26 & -8.64 & 29 & -18 \\
\hline Meat and processed meat products & 21 & 11.34 & 20 & -4.93 & 21 & -6.19 \\
\hline Biscuits & 22 & 11.45 & 19 & -12.7 & 18 & -19.57 \\
\hline Honey, jam, concentrated grape juice & 23 & 11.47 & 28 & -11.61 & 25 & -7.36 \\
\hline Chocolate cream spread & 24 & 12.11 & 21 & -6.31 & 23 & -6.84 \\
\hline Crisps & 25 & 13.37 & 17 & -3.57 & 17 & -4.55 \\
\hline Sweets, candies & 26 & 13.39 & 31 & -14.43 & 28 & -14.77 \\
\hline Cheeses & 27 & 14.02 & 5 & 3.21 & 16 & -2.66 \\
\hline Chocolate-coated wafers & 28 & 15.65 & 22 & -7.01 & 27 & -13.71 \\
\hline Cakes & 29 & 16.32 & 30 & -12.7 & 30 & -19.54 \\
\hline Chocolates & 30 & 17.61 & 25 & -8.14 & 26 & -10.88 \\
\hline Vegetable oils and spreads & 31 & 18.78 & 15 & -2.78 & 14 & -2 \\
\hline
\end{tabular}




\section{DISCUSSION}

Nutrient profiling is an objective and scientific method that calculates the nutritional quality of foods and beverages (5). When considering regulatory applications of nutrient profiling, it can be used as the basis for health claims and advertising aimed at children. As an educational tool, nutrient profiling can be used in consumer education, to promote healthy diets and to discourage unhealthy eating behaviours (7).

In nutrient profiling models, energy density, water content, and the serving size of the foods and beverages are important criteria for deciding if the foods and beverages are healthy or not (21).

Consistent positive results were found for the pasta, grains and legumes, frozen and canned foods, ayran (diluted yoghurt), yoghurt and milk, and consistent negative results were obtained for vegetable oils and spreads, chocolates, cakes, crisps, chocolate cream spread, fruit and vegetable juices, honey, jam, sweets and candies. The models calculate opposite results for soda with fruit flavour, cheeses, flavoured milk, nuts and dried fruits.

The WXYfm model is based on the energy and saturated fat content of the foods and beverages, so the more energy dense foods tend to be less healthy in this model. With respect to energy values, the WXY fm model scores correlated moderately with the foods $(r=0.557, p<0.05)$. The saturated fat content of a food is one of the main criteria for deciding whether the food or beverage is healthy in this model. The protein content of foods is considered to be positive in the score of this model so the high protein content of the foods and beverages tend to be considered healthier (6). In this study, meat and meat product scores were found to be unexpectedly high and considered as less healthy in this model. Meat and meat products include salami, sausages, sucuk (dryfermented sausage), jambon, pastirma (a type of dry-cured meat product), and chicken meat. The saturated fat and sodium content of these products are generally high. This can be an explanation as to why in this study we found meat products to be less healthy.

The NRF 9.3 model calculation is based on the twelve nutrient contents of foods and beverages. With the NRF 9.3 model, foods and beverages were evaluated according to serving size and $100 \mathrm{kcal}$ content of a food. The scores for milk, yoghurt and diluted yoghurt with this model were high. The flavoured milk score was the worst among milk products in the NRF 9.3 model. Calculations were made per $100 \mathrm{kcal}$ of the foods and beverages and the portion size of the products. This calculation may mislead the model for some of the low energy density foods and beverages, while for vegetables and fruits, the $100 \mathrm{kcal}$ basis may be in excess of the portion size consumed (when nutrient profiles are $100 \mathrm{kcal}$ or $100 \mathrm{~g}$ ). It seems more convenient to use a model that includes portion size, however, portion size may vary in different countries. In this study, calculations of the per portion size and per $100 \mathrm{kcal}$ correlated. This indicates that this model can be used with the Turkish portion sizes.

Cheeses are considered to be less healthy in the WXYfm model compared to the NRF 9.3 model. This is due to the sodium and saturated fatty acid content of cheese that the WXYfm model categorizes as being in the less healthy category. On the other hand, the NRF 9.3 model considers cheeses as good because of the calcium and other essential nutrient contents of the food. Models WXY fm and NRF 9.3 have nearly the same results for milk.
The WXYfm model was generated for regulating food and beverage advertisements for children to control the saturated fats, added sugars and salt content of the products. The NRF 9.3 index was aimed to educate consumers and evaluate the nutritional quality of food and beverages. The results of this study confirmed that the results from the two different models correlated.

The WXYfm model is a simple scoring model and gave the best scores for foods and beverages low in energy, saturated fats, added sugars, and sodium. The NRF 9.3 index model is a continuous function mainly focused on three negative nutrients (saturated fats, added sugars and sodium) and nine positive nutrients. In this study, the WXYfm and NRF 9.3 index nutrient profiling models were used for labelled foods and beverages in Turkey and gave consistent results in ranking food and beverage groups. The WXYfm model is much more correlated with energy value than the NRF index model.

The limitation of this study was obtaining the nutrient labels of the packaged foods. Food composition tables and the BEBIS program were used for some of the missing nutrient labels on packaged foods. The status of nutrient labelling in Turkey and the nutrient content of the packaged products were assessed by this research. This study shows that nutrient profiling is possible to use for providing objective information about nutrient contents of packaged food in order to help healthier choices made by the consumers.

Further research is needed using other category specific nutrient profiling models to understand how these models behave and how they can be used to develop a proper nutrient profiling model for Turkey.

\section{Acknowledgements}

We thank Dr. Adam Drewnowski for his helpful comments to improve the manuscript. G.P., and D.D. designed the research project. D.D. conducted the research, completed all analyses and had primary responsibility for all parts of the manuscript. D.D., M.K. M.F.U. and G.P. gave input on the content of the paper and read and approved the final manuscript.

\section{Conflict of Interests}

None declared

\section{REFERENCES}

1. Alwan A, editor. Global status report on noncommunicable diseases 2010. Geneva: World Health Organization; 2010.

2. Diet, nutrition and the prevention of chronic diseases: Report of a Joint WHO/FAO Expert Consultation. WHO technical report series 916. Geneva: WHO; 2003.

3. Azaïs-Braesco V, Goffi C, Labouze E. Nutrient profiling: comparison and critical analysis of existing systems. Public Health Nutr. 2006 Aug;9(5):613-22.

4. European Food Safety Authority. The setting of nutrient profiles for foods bearing nutrition and health claims pursuant to Article 4 of the Regulation (EC) No 1924/2006 - Scientific Opinion of the Panel on Dietetic Products, Nutrition and Allergies. EFSA J. 2008;644:1-44.

5. World Health Organization. Nutrient profiling: Report of a WHO/IASO technical meeting, London, United Kingdom 4-6 October 2010. Geneva: WHO; 2011.

6. Quinio C, Biltoft-Jensen A, De Henauw S, Gibney MJ, Huybrechts I, McCarthy SN, et al. Comparison of different nutrient profiling schemes to a new reference method using dietary surveys. Eur J Nutr. 2007 Dec;46 Suppl 2:37-46. 
7. Drewnowski A. What's next for nutrition labeling and health claims? An update on nutrient profiling in the European Union and the United States. Nutr Today. 2007 Sep-Oct;42(5):206-14.

8. Scarborough P, Boxer A, Rayner M, Stockley L. Testing nutrient profile models using data from a survey of nutrition professionals. Public Health Nutr. 2007 Apr;10(4):337-45.

9. Drewnowski A. Concept of a nutritious food: toward a nutrient density score. Am J Clin Nutr. 2005 Oct;82(4):721-32.

10. Drewnowski A, Fulgoni V 3rd. Nutrient profiling of foods: creating a nutrient-rich food index. Nutr Rev. 2008 Jan;66(1):23-39.

11. Drewnowski A. The Nutrient Rich Foods index helps to identify healthy, affordable foods. Am J Clin Nutr. 2010 Apr;91(4):1095S-1101S.

12. Drewnowski A. Defining nutrient density: development and validation of the nutrient rich foods index. J Am Coll Nutr. 2009 Aug;28(4):421S$426 \mathrm{~S}$.

13. European Commission Health and Consumers Directorate-General. Working document on setting of nutrient profiles: preliminary draft legal proposal [Internet]. Brussels: European Commision; 2009 [cited 2010 Oct 10]. Available from:

http://www.senat.fr/europe/textes europeens/a0006.pdf.

14. Baysal A, Keçecioğlu S, Arslan P, Yücecan S, Pekcan G, Güneyli U, et al. 3rd ed. Composition of foods. Ankara: Türkiye Diyetisyenler Derneği; 1991. (In Turkish.)

15. Schmid, M. BeBiS 6.1 Ebispro for Windows, Stuttgart, Germany; Turkish version BeBiS; Data Bases: Bundeslebenmittelschlüssell, 11.3 and USDA 15. Istanbul: 2004.
16. Rayner M, Scarborough P, Stockley L, Boxer A. Nutrient profiles: further refinement and testing of Model SSCg3d. Final report [Internet]. Oxford: University of Oxford; 2005 [cited 2010 Jul 10]. Available from: http:// www.food.gov.uk/multimedia/pdfs/npreportsept05.pdf.

17. Department of Health. Nutrient profiling technical guidance January 2011 [Internet]. London: Department of Health; 2011 [cited 2013 Feb 10]. Available from: https://www.gov.uk/government/uploads/system/ uploads/attachment_data/file/216094/dh_123492.pdf.

18. Arambepola $\mathrm{C}$, Scarborough $\mathrm{P}$, Rayner M. Validating a nutrient profile model. Public Health Nutr. 2008 Apr;11(4):371-8.

19. Fulgoni V 3rd, Keast DR, Drewnowski A. Development and validation of the nutrient-rich foods index: a tool to measure nutritional quality of foods. J Nutr. 2009 Aug;139(8):1549-54.

20. Republic of Turkey Ministry of Food. Agriculture and livestock Turkish food codex food labeling regulation. Off Gaz Rep Turkey [Internet]. 2011 Dec 29 [cited 2012 Aug 20]; No. 28157. Available from: http://mevzuat. basbakanlik.gov.tr/Metin.Aspx?MevzuatKod=7.5.15691\&MevzuatIlisk $\mathrm{i}=0 \&$ sourceXmlSearch=g1da. (In Turkish.)

21. Arambepola C, Scarborough P, Boxer A, Rayner M. Defining 'low in fat' and 'high in fat' when applied to a food. Public Health Nutr. 2009 Mar;12(3):341-50.

Received November 25, 2013 Accepted in revised form January 1, 2015 